\title{
CRISE HÍDRICA NO DISTRITO FEDERAL: O CASO DA BACIA DO RIO PRETO
}

\author{
MESQUITA, Luís Fabio Gonçalves - olhaomesca@gmail.com \\ Universidade de Brasília / UNB \\ LINDOSO, Diego - diegoplindoso@gmail.com \\ Universidade de Brasília / UNB \\ RODRIGUES FILHO, Saulo - saulofilhocds@gmail.com \\ Universidade de Brasília / UNB
}

\begin{abstract}
RESUMO: As raízes da crise hídrica vão além da questão climática, perpassando causas antrópicas como as políticas de uso e ocupação do solo e de gestão hídrica. Para analisar o problema, o presente artigo adota o arcabouço da vulnerabilidade, amplamente aplicado na literatura sobre mudança climática. Utilizando como foco da pesquisa a Bacia Hidrográfica do Rio Preto, localizada no território do Distrito Federal, pretende-se contribuir no debate da governança climática adaptativa visando subsidiar a tomada de decisão na gestão hídrica. Além dos dados secundários, foram inseridos na análise dados extraídos em atas de reunião, observação direta e entrevistas com membros do Comitê de Bacia Hidrográfica dos Afluentes do Rio Preto. O texto mostra os desafios da gestão no comitê e a vulnerabilidade hídrica existente na bacia.
\end{abstract}

PALAVRAS-CHAVE: Governança climática; Comitê de Bacia Hidrográfica; Vulnerabilidade; Bacia Hidrográfica do Rio Preto.

WATER CRISIS IN THE FEDERAL DISTRICT: THE CASE OF THE RIO PRETO BASIN

\begin{abstract}
The origin of water crisis is not only about climate. It has also to be considered human causes, such as territorial and water policies. In order to analyze this issue, the present paper adopts the vulnerability approach, frequently used in climate change literature. Using the research area of the Rio Preto Watershed, in Distrito Federal territory, it is intended to contribute on the debate of climate adaptive governance aiming at guiding decision making process in water management. Along with literature data, it was analyzed minutes, direct observation and interviews with members of Rio Preto Watershed Committee. The paper points out the challenges faced by the committee and the water security vulnerability in Rio Preto Watershed.
\end{abstract}

KEYWORDS: Climate governance; Watershed Committee; Vulnerability; Rio Preto Watershed.

\section{INTRODUÇÃO}

A água é um recurso natural vital que, além de fornecer condições básicas para sobrevivência das diferentes espécies e de manter o equilíbrio dos ecossistemas terrestres, é fundamental para garantir o desenvolvimento territorial e econômico.

A crise hídrica que se abateu sobre o Distrito Federal (DF) no período entre os anos de 2015 e 2017 é sem precedentes, tanto para a zona urbana quanto para a zona rural. O risco de desabastecimento humano e a redução da produção rural são ameaças concretas. Se a estação chuvosa dos anos 2018/2019 seguir as tendências dos anos anteriores de precipitações abaixo da média, o cenário será catastrófico para a segurança hídrica urbana e rural. As raízes da crise vão além da questão climática, perpassando causas antrópicas como as políticas de uso e ocupação do solo e de gestão hídrica. Para analisar o 
problema, o presente artigo adota o arcabouço da vulnerabilidade, amplamente aplicado na literatura sobre mudança climática e gestão de riscos de desastres naturais (BAD, 2018; CHAVES, 2011; CHENG, 2004; MARANDOLA; HOGAN, 2004).

A vulnerabilidade é entendida como susceptibilidade de um sistema em sofrer danos, prejuízos e impactos, assim como a incapacidade de prevenir e lidar com esses (SMIT et al, 2001). A vulnerabilidade pode ser definida como função de três atributos: exposição, sensibilidade e capacidade adaptativa (LINDOSO et al, 2011). A exposição refere-se ao vetor de distúrbio, externo aos sistemas afetados, e que pode ser descrito segundo sua natureza, frequência, magnitude, duração (FÜSSEL; KLEIN, 2006; SMITHERS; SMIT,1997). Geralmente é o vetor ambiental, como o climático, mas também pode ser fator social (guerras), econômico (globalização) ou tecnológico (acidentes nucleares) (O'BRIEN; LEICHENKO, 2000; WHITE et al, 2001; O'BRIEN et al, 2004). A sensibilidade descreve as características internas dos sistemas que, ao interagirem com os vetores de exposição, determinam a magnitude do impacto (ADGER, 2006; GALLOPÍN, 2006). As sensibilidades são, portanto, vetorespecífico e sintetizadas em alguns trabalhos em um único termo: exposiçãosensibilidade (FORD et al, 2006).

A relação exposição-sensibilidade pode ser moderada por meio de adaptações, outro conceito central na literatura sobre mudança do clima. A adaptação é entendida como todo ajuste nos sistemas sob estresse que reduza sensibilidades, aproveite oportunidades ou fomente capacidade adaptativa frente aos efeitos adversos do clima, presentes ou futuros (LINDOSO, 2015). Neste debate, a capacidade adaptativa, o último atributo da vulnerabilidade, é definida como o conjunto de condições que viabiliza a implementação de uma determinada adaptação. Trata-se de um conceito de caráter potencial, de modo que a alta capacidade adaptativa não necessariamente implica adaptação, dependendo de agentes que implementem o potencial em questão. Capacidade adaptativa pode ser caracterizada pela gama de opções adaptativas disponíveis e os meios para acessá-las (NORBERG; CUMMING, 2008). No que se refere aos meios, esses podem ser diversos, desde recursos financeiros em adaptações que demandam investimentos, à habilidade de comunicar e expressar as medidas adaptativas que exijam acesso à informação escrita.

A literatura sobre capacidade adaptativa dá grande enfoque a análises de governança que subjazem o processo adaptativo, referidos como gestão adaptativa e governança adaptativa (ADGER, 2006; ADGER; KELLY, 1999). Dentro desta ótica, são defendidos modelos flexíveis de governança que reconheçam em sua formulação o ambiente como realidade instável e imprevisível, ao mesmo tempo em que são capazes de se ajustar à medida que novos aprendizados surjam durante o processo de implementação (ANA, 2018; BABEL; SHINDE, 2018; DIETZ et al, 2003; HOLLING; MEFFE, 1996). A governança climática adaptativa é o conjunto de decisões, atores, processos, estrutura e mecanismos institucionais - incluindo a divisão de autoridade e suas regras implícitas - que determinam ajustes nos sistemas socioecológicos tendo em vista torná-los mais resilientes ou menos vulneráveis ao estresse climático (MOSER, 2009). Ela é flexível, permitindo interferência em Planos, Programas e Ações de adaptação ao longo de todo o processo de implementação, inclusive transitar para outras opções adaptativas quando as inicialmente adotadas se mostrarem desinteressantes. Nessa perspectiva, a gestão climática constitui 
uma experiência política, na qual os resultados são constantemente monitorados e avaliados, de modo que as conclusões servem de inputs para aprimorar o processo político (GUNDERSON et al, 2008).

Considerando a governança climática adaptativa é oportuno mencionar a criação do Sistema Nacional de Gerenciamento de Recursos Hídricos e a instituição da Política Nacional dos Recursos Hídricos, regidos pela Lei n0 9.433 de 08 de janeiro de 1997. Essa lei estabeleceu um novo modelo de gestão, instituindo novos atores e instituições no gerenciamento dos recursos hídricos de forma decentralizada. A instituição dos Comitês de Bacias Hidrográficas (CBHs) reflete esse novo modelo de gestão, incluindo a participação da sociedade civil, do poder público e dos usuários da bacia hidrográfica no processo de tomada de decisão. Os CBHs são responsáveis, entre outras atribuições, por arbitrar os conflitos de uso de água na bacia, sugerir mecanismos de cobrança e valores pelo uso dos recursos hídricos, definir prioridades de outorga, aprovar projetos e o Plano de Recursos Hídricos da bacia.

Na porção leste do território do Distrito Federal está localizada a Bacia Hidrográfica do Rio Preto, área de jurisdição do Comitê de Bacia Hidrográfica dos Afluentes do Rio Preto-CBH/AP. Essa área é ocupada por atividades predominantemente agrícolas com uso expressivo de pivôs centrais de irrigação que têm contribuído para a redução da disponibilidade hídrica para os usuários da bacia, principalmente no período de estiagem (MACHADO, 2009). A demanda por uso de água para irrigação em algumas unidades hidrográficas inseridas na Bacia Hidrográfica do Rio Preto é maior do que a disponibilidade de água (DISTRITO FEDERAL, 2012). Os produtores rurais inseridos nessa bacia, inclusive os produtores membros no $\mathrm{CBH} / \mathrm{AP}$, perceberam a escassez de água em suas propriedades previamente à instalação da crise hídrica para abastecimento humano nas áreas urbanas do Distrito Federal. A redução das precipitações restringiu a disponibilidade de água na bacia e obrigou os produtores rurais a reduzirem suas áreas de plantio para irrigação, causando perdas na produção em suas propriedades. Diante dessa situação, o governo do Distrito Federal decretou estado de emergência nas áreas agrícolas de sua jurisdição devido à redução no volume de chuvas nos meses de fevereiro, março e abril do ano de 2016.

É neste contexto que o presente trabalho se insere. Empreende-se uma análise do funcionamento do Comitê da Bacia Hidrográfico dos Afluentes do Rio Preto na gestão adaptativa da bacia em ano de crise hídrica no DF. O Comitê é central dentro do paradigma da descentralização da política hídrica brasileira e funciona, na prática, como peça fundamental da governança climática.

\section{2. ÁREA DE ESTUDO}

A Bacia Hidrográfica do Rio Preto faz parte da Bacia Hidrográfica do Rio São Francisco e compreende uma área de aproximadamente 1.045 .900 hectares, inserida nos Estados de Goiás, Minas Gerais e do Distrito Federal (figura 1). 


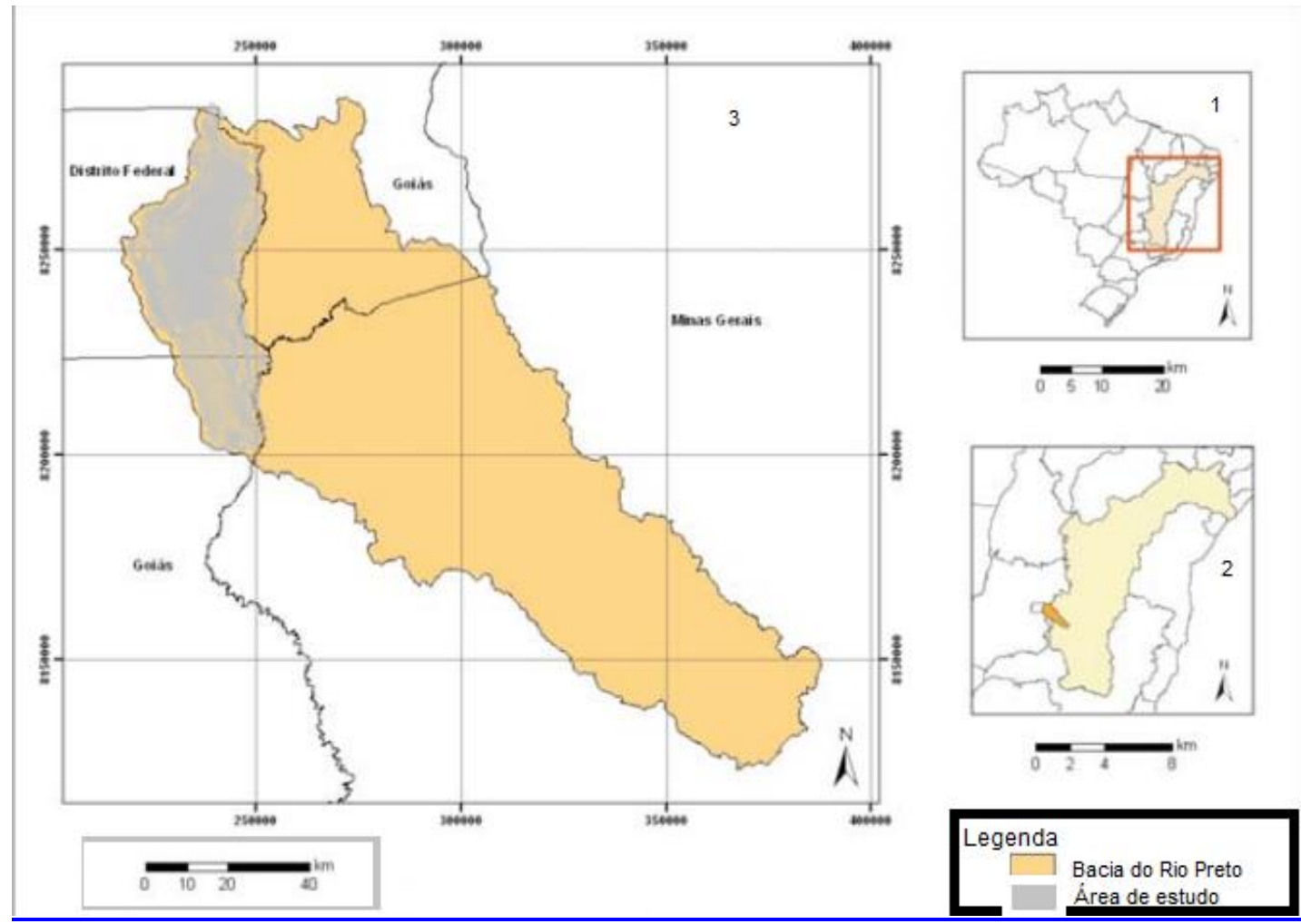

Figura 1 - Localização da Bacia Hidrográfica do Rio Preto (3) em relação à Bacia Hidrográfica do Rio São Francisco (1 e 2). Fonte: Adaptado de Borges et al., 2007.

No Distrito Federal, a Bacia Hidrográfica do Rio Preto está localizada na porção leste e compreende uma área de aproximadamente 131.300 hectares, representando $22,5 \%$ do seu território. O uso do solo nesta região é eminentemente rural e responsável por cerca de $80 \%$ da produção agrícola do DF (CARNEIRO, et al 2007). As principais culturas produzidas pelos médios e grandes produtores nessa porção territorial são a soja, o milho, o feijão e o sorgo. O uso de água predominante nestas propriedades é a irrigação por meio de pivôs centrais. A Bacia do Rio Preto possui aproximadamente 230 pivôs que irrigam uma área de 14.000 hectares. Cerca de $86,6 \%$ do consumo total das captações superficiais na Bacia do Rio Preto são utilizados para irrigação de culturas (DISTRITO FEDERAL, 2012). No que se refere aos pequenos produtores, os principais cultivos são hortaliças, alho, batata, tomate, limão e pimentão.

Estudos indicam que a capacidade de suporte da exploração dos recursos hídricos na Bacia do Rio Preto para irrigação já está próxima do limite em alguns mananciais e já foi ultrapassada em outros, indicando a necessidade de um forte sistema de gestão de recursos hídricos na bacia (PARRON e OLIVEIRA, 2007). Em decorrência da diminuição das precipitações, os produtores rurais na Bacia do Rio Preto tiveram redução de aproximadamente $30 \%$ de sua área irrigada. Além dos conflitos pelo uso da água acirrados entre os irrigantes, há conflitos entre os usuários irrigantes e a operação da Usina Hidrelétrica de Queimados, localizada à jusante das culturas irrigadas e inserida no território do DF e do Estado de Minas Gerais. Os usuários não irrigantes presentes na bacia também 
estão inseridos nos usos concorrentes da água. Portanto, estão expostos à vulnerabilidade climática diferentes usuários na bacia.

\section{MATERIAIS E MÉTODOS}

Esta pesquisa buscou alcançar seu objetivo com foco na literatura que trata da governança climática adaptativa relacionando essa com a crise hídrica no Distrito Federal. Para elucidar essa relação foi apresentado um estudo de caso na Bacia Hidrográfica do Rio Preto no DF. A análise da governança climática foi realizada no âmbito do Comitê de Bacia Hidrográfica dos Afluentes do Rio Preto evidenciando os atributos de vulnerabilidade.

Os dados apresentados e analisados neste artigo foram coletados de trabalhos acadêmicos (teses, dissertações, artigos científicos) e dados gerados por instituições de pesquisa e entidades governamentais.

Na pesquisa de estudo de caso na Bacia Hidrográfica do Rio Preto foram entrevistados os membros do Comitê de Bacia Hidrográfica dos Afluentes do Rio Preto no período do segundo semestre do ano de 2016 ao primeiro trimestre do ano de 2017. Foram entrevistados 18 membros do Comitê de Bacia Hidrográfica dos Afluentes do Rio Preto, sendo que 10 membros representavam o poder público, 05 a sociedade civil e 03 os usuários de água na bacia. As entrevistas foram realizadas seguindo roteiro semi-estruturado que permitiu traçar o perfil e as percepções dos membros do comitê, apontar os aspectos positivos e negativos da gestão do comitê, conhecer a área de atuação dos membros, identificar as demandas, problemas e potenciais conflitos de uso da água na Bacia Hidrográfica do Rio Preto. Além das entrevistas, adotou-se também a metodologia da observação não participante em que se participou de reuniões ordinárias e extraordinárias realizadas pelo Comitê de Bacia Hidrográfica dos Afluentes do Rio Preto no ano de 2016 e no primeiro trimestre do ano de 2017. Para ampliar ainda mais essa análise foram realizadas pesquisas documentais nas atas de reuniões do comitê desde o ano de sua criação (2010) até o primeiro trimestre de 2017 (36 atas ao total).

O acesso de informações por múltiplas fontes para o desenvolvimento da pesquisa, ao mesmo tempo que amplifica a análise, permite que, por meio da análise de conteúdo dos dados, sejam incorporados aspectos específicos que poderiam ser negligenciados se obtidos por uma única fonte.

\section{RESULTADOS E DISCUSSÃO}

Em função das chuvas inferiores à média histórica e das temperaturas máximas extremas, a vazão dos rios que fluem para os reservatórios dos sistemas de abastecimento e das usinas hidrelétricas das regiões Sudeste e Centro-Oeste, de elevado consumo de energia, atingiu a menor marca da história (MARENGO et al, 2015).

Os vetores de exposição climáticos durante a crise hídrica do DF são sintetizados na figura 2. As estações chuvosas dos anos de 2015/2016 e de 2016/2017 foram abaixo da média histórica. A figura 2 destaca que as temperaturas compensadas durante a estação seca (junho-outubro) apresentaram uma tendência de alta a partir da década de 1990, com uma 
substancial inflexão a partir de 2014. A investigação não se dedica a entender as causas desses comportamentos, de modo que os dados não permitem afirmar que uma mudança na normal climática, tanto nas temperaturas quanto nas chuvas, ocorreu ou está em curso, pois pode ser uma microtendência da variabilidade natural. Entretanto, são suficientes para entender que o contexto climático desfavorável da atual crise hídrica não se restringe apenas a falta de chuvas, uma vez que não são inéditas na série histórica.
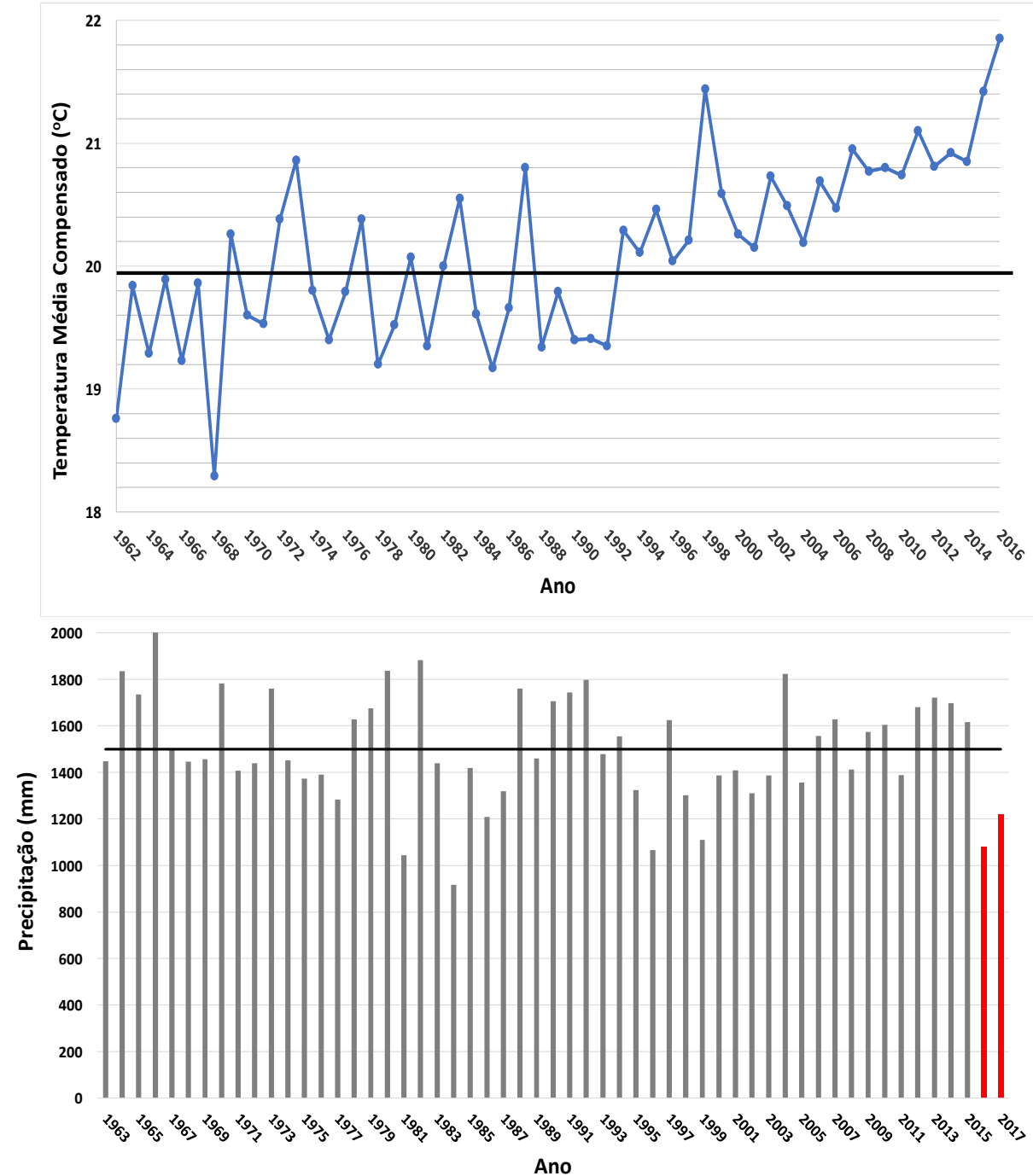

Figura 2 - Série histórica das temperaturas médias compensadas (oC) e precipitações anuais da estação Brasília-DF (OMM:83377). O ano pluviométrico compreende 12 meses entre junho do ano anterior até maio do ano em questão. As médias do período são indicadas pela linha horizontal negra. A temperatura média compensada compreende os meses da estação seca (junho-outubro), quando a evapotranspiração é mais acentuada. Fonte: LINDOSO; RODRIGUES-FILHO, 2016.

A falta de planejamento estratégico fica evidenciada quando a previsão de escassez hídrica vinha sendo anunciada. Estudos da década de 1990 como o de Dolabella (1996) já anunciavam o risco de escassez de água no Distrito Federal. Além da falta de planejamento de longo prazo, também deve ser levado 
em consideração o aumento das temperaturas que implicam taxas mais elevadas de evapotranspiração na bacia hidrográfica, assim como a contribuição para a queda mais acentuada da umidade relativa do ar, que retroalimenta as perdas evaporativas.

Uma vez caraterizados os vetores de exposição climáticos, o segundo passo é identificar as sensibilidades climáticas. Analisar a cadeia de impactos fornece pistas importantes (figura 3).

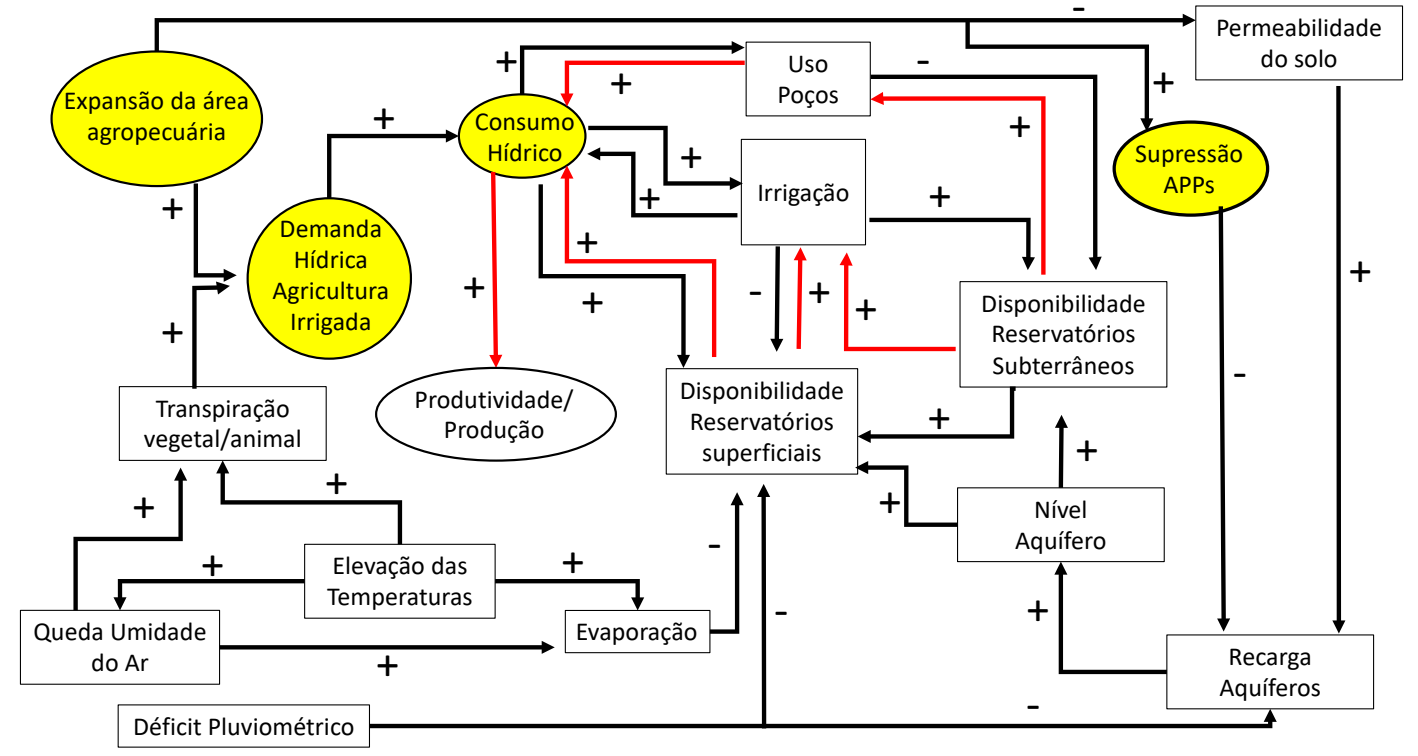

Figura 3 - Cadeia de relações entre agropecuária e uso da água na Bacia Hidrográfica do Rio Preto durante a crise hídrica do DF 2016-2017. (+): relações proporcionais; (-): relações inversamente proporcionais. As setas vermelhas representam retroalimentações que ocorrem quando os níveis dos reservatórios atingiram um nível que não permite atender à demanda hídrica da agropecuária. As elipses amarelas indicam pontos de intervenção adaptativa (Fonte: elaborado pelos autores)

As condições climáticas severas de 2015/2016 e 2016/2017 impactaram diretamente o volume de água disponível na bacia hidrográfica, tanto na entrada menor de água no sistema via precipitações, quanto no aumento das perdas por evaporação. A quantidade de água que é retida e perdida depende também de características (sensibilidades) da área da bacia, como topografia (áreas mais planas favorecem percolação para armazenagem nos aquíferos, áreas mais inclinadas favorecem o escoamento superficial e exportação para fora em áreas à jusante), uso do solo (áreas vegetadas tem maior percolação que áreas antropizadas), natureza dos aquíferos (se sedimentares ou fraturados), área de superfície das lâminas de água (menor a relação entre superfície e volume, maior as perdas evaporativa). Na Bacia do Rio Preto predominam áreas com topografia mais plana, o que favorece a infiltração da água e o desenvolvimento de atividades agrícolas. Contudo, as Áreas de Preservação Permanentes (APPs) e as Reservas Legais na maioria das propriedades estão descaracterizadas, o que compromete os reservatórios superficiais e subterrâneos. 
De relevância especial para este trabalho estão as sensibilidades de construção humana. Primeiro, a elevação das temperaturas e redução da umidade do ar estressam os sistemas agropecuários por perdas transpirativas e impactos nas taxas fotossintéticas dos cultivos agrícolas. Nesse nível, as sensibilidades estão associadas a aspectos fisiológicos das plantas e animais. Em conjunto com a expansão da área agropecuária, o estresse hídrico dos sistemas agroprodutivos avançam na cadeia de impactos elevando a demanda global por água na bacia hidrográfica (Figura 3). Na pesquisa de Lima et al (2017), em que foram coletados dados qualitativos por entrevistas dos produtores rurais que utilizam pivôs centrais na Bacia do Rio Preto, mesmo diante da crise hídrica na região, um percentual expressivo dos entrevistados $(34,3 \%)$ tinha interesse em ampliar a área irrigada em suas propriedades. O aumento da demanda leva ao aumento do consumo hídrico do setor, que capta água nos reservatórios subterrâneos e superficiais. A área da Bacia do Rio Preto contém o maior número e densidade de outorgas de captação superficial do DF. Isso mostra a pressão exercida sobre os recursos hídricos da região, exigindo maior investimento em gestão.

Portanto, o consumo hídrico de culturas irrigadas é um fator de sensibilidade da bacia, uma vez que é característica interna, indiretamente interagindo com vetor de exposição climático e que exerce pressão sobre os reservatórios hídricos. A área agrícola também entra como fator de sensibilidade climática em outras dimensões, como ao substituir a vegetação nativa por formas de uso e ocupação do solo de menor permeabilidade a água da chuva. A supressão ou intervenções na vegetação nativa de Áreas de Proteção de Mananciais-APM e Áreas de Preservação Permanente-APPs (veredas, matas de galeria e ciliares, nascentes), essenciais à manutenção da vazão superficial durante a estação seca, é um exemplo de sensibilidade presente na Bacia do Rio Preto. Quanto menor permeabilidade do solo, menor a percolação da água, reduzindo assim a recarga dos aquíferos (figura 3). Essa ocupação desordenada, contrariando a legislação ambiental, resulta no aumento do escoamento superficial associado à erosão do solo e ao assoreamento dos corpos de água superficiais, reduzindo a capacidade de retenção hídrica nas áreas de captação. $\mathrm{Na}$ pesquisa de Lima et al (2017) foi constatado que mais de $50 \%$ dos proprietários rurais entrevistados fazem captação de água próximo às nascentes na Bacia do Rio Preto. Isso mostra a necessidade de discussão sobre o uso da água em regiões de nascentes ou de recarga de aquíferos entre os tomadores de decisão para gerar base legal e operacional no uso racional e controlado da água nessas áreas de interesse ambiental coletivo. O Zoneamento Ecológico Econômico do Distrito Federal-ZEE/DF, em fase de discussão, é um instrumento capaz de orientar essa racionalidade. Contudo, se não houver a participação efetiva da academia, instituições de pesquisa, especialistas e da população, o ZEE/DF não terá capacidade de estabelecer as diretrizes necessárias para garantir a sustentabilidade hídrica das bacias hidrográficas do Distrito Federal (MESQUITA, 2017).

Mesmo sobrecarregando as fontes hídricas (consumo maior que a recarga), enquanto houver disponibilidade de água na bacia e uso não racional, em tese, as demandas poderiam e, possivelmente, seriam atendidas até o limite de oferta das fontes hídricas, tanto subterrâneas quanto superficiais. Ultrapassados os limites, a oferta seria deficitária e os sistemas agropecuários seriam afetados na produção/produtividade e segurança hídrica. Esse sistema 
de retroalimentação negativo está destacado pelas setas vermelhas na figura 3 a fim de ressaltar que o consumo excessivo e perda de permeabilidade do solo (sensibilidades), em conjunto com condições climáticas desfavoráveis (exposição), leva ao comprometimento da capacidade da bacia em atender ao próprio consumo agropecuário. Na sub-bacia do Ribeirão Extrema, inserida na Bacia do Rio Preto, a demanda por água já supera a oferta. Considerando o grande número de usuários irrigantes nessa sub-bacia, a Agência Reguladora de Águas, Energia e Saneamento do Distrito Federal-ADASA/DF, responsável por conceder as autorizações de captação de usos de água, com o apoio da Empresa de Assistência Técnica e Rural do Distrito Federal-EMATER/DF, tem promovido a alocação negociada da água entre os irrigantes. O processo consiste em uma negociação entre os produtores irrigantes, supervisionados pelo poder público, em que é definido uma alternância na irrigação das culturas. Os irrigantes são divididos em três grandes grupos em que é definido o horário de irrigação para cada grupo, a fim de evitar a pressão nas vazões dos cursos de água da bacia. Contudo, como não há medidores de vazões nos equipamentos dos usuários e devido à ausência de mecanismos de controle das outorgas de uso de água, a alocação de água realizada na bacia necessita de aprimoramento na implantação. Conforme relatado por representante do setor agrícola, membro do $\mathrm{CBH} / \mathrm{AP}$, alguns produtores ainda não incorporaram a disciplina regida no processo de alocação de água.

"Existem acordos nas reuniões com os produtores, cada um usar água em um determinado período, mas a gente sabe que às vezes algum não cumpre o que foi acordado e acaba utilizando mais... e gera pequenos conflitos."

Essas negociações ocorrem fora do âmbito do Comitê de Bacia Hidrográfica dos Afluentes do Rio Preto, que seria a instituição responsável por arbitrar esses conflitos. Na realidade, o comitê não consegue executar a maioria das atribuições que lhe foram conferidas pela legislação. O predomínio de grandes irrigantes; a ausência de pequenos produtores e de representantes da academia e da sociedade civil com finalidade de proteção ambiental e a escassez de recursos humanos e financeiros têm contribuído para o enfraquecimento da gestão dos recursos hídricos na Bacia do Rio Preto pelo comitê. Apesar dessas dificuldades, o comitê tem avançado nas reuniões com exposições de informações científicas pela EMBRAPA Cerrados no que se refere a real situação dos corpos hídricos de sub-bacias experimentais. Na sub-bacia experimental do Rio Jardim, monitorada de forma robusta pela EMBRAPA Cerrados, foi verificado que houve um rebaixamento do nível do lençol freático de aproximadamente 4 metros no período de 2005 a 2016. Apesar da resistência em confiar nos dados por alguns produtores rurais mais conservadores, a conscientização ambiental e a necessidade de uso racional da água na bacia vem sendo incorporada gradativamente nos produtores.

Na pesquisa de Madruga et al (2011), em que foram coletadas fontes primárias (entrevistas e reuniões) e secundárias (pesquisa documental), constatou-se que o Comitê de Santa Maria, localizado no Rio Grande do Sul, foi capaz de inserir o comportamento coletivo onde predominava ações individualizadas. A ampliação do nível de consciência dos envolvidos a partir do 
conhecimento gerado pelas universidades e especialistas, a mudança de postura dos usuários em relação ao rio e aos problemas ambientais, o fortalecimento da malha institucional e a mudança de percepção da comunidade acerca do papel do comitê trouxeram mudanças qualitativas na gestão dos recursos hídricos na bacia. Chama a atenção nesse comitê que $80 \%$ dos membros são representantes da sociedade civil e usuários da bacia, restando $20 \%$ das vagas destinadas ao poder público. Portanto, apesar das dificuldades operacionais existentes no $\mathrm{CBH} / \mathrm{AP}$, o comitê tende a se fortalecer à medida que vai incorporando conhecimento científico e o interesse coletivo de forma planejada nas suas ações. Os vetores de exposições climáticas na Bacia do Rio Preto tornam a gestão dos recursos hídricos pelo comitê desafiadora.

No caso da cadeia de impactos representada na figura 3, os vetores de exposição climáticos não são passíveis de controle pela governança hídrica local. Tem na variabilidade climática natural e fatores antropogênicos de dinâmica regional e global causas para além do escopo de atuação de comitês, agências reguladoras, sociedade civil e usuários. Todavia, os fatores de sensibilidade estão sob o alcance da ação local. Os pontos de intervenção adaptativas são diversos.

Um conjunto de adaptação pode centrar na adoção de variedades agropecuárias resistentes ao estresse hídrico, tecnologias agrícolas mais eficientes no uso do recurso, como o uso de sistemas de irrigação menos intensivos em água (gotejamento e microaspersão) e técnicas de conservação de água no solo (plantio direto, terraceamento, bacias de contenção, proteção e recuperação de APP e reserva legal). Na Bacia do Rio Preto, a maioria dos produtores rurais que utilizam pivôs centrais para irrigação de suas culturas utilizam o plantio direto em suas propriedades (figura4).

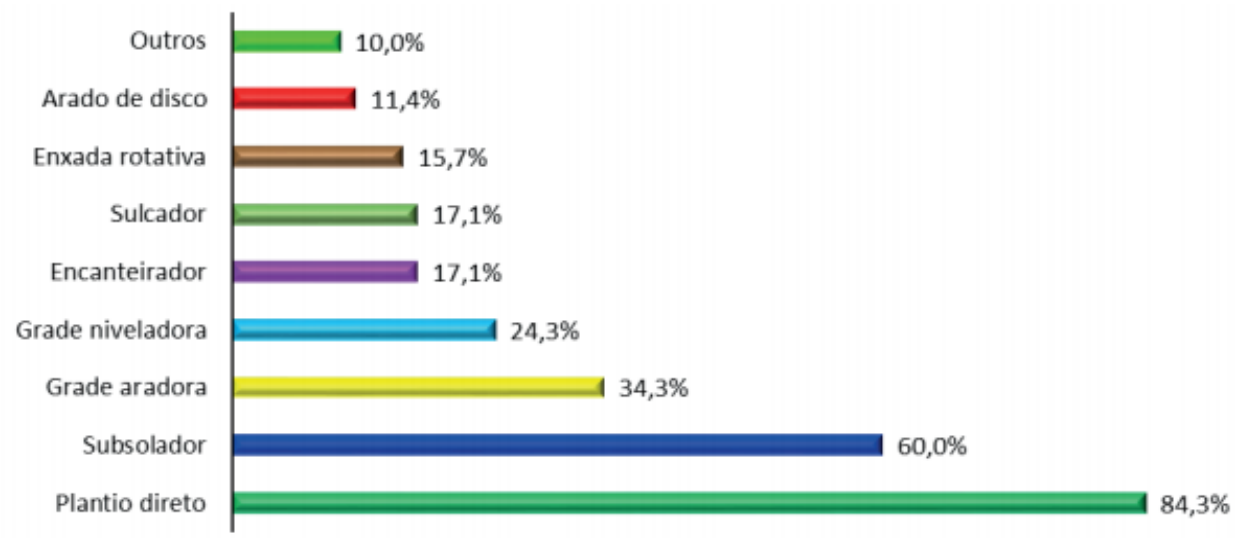

Figura 4 - Preparo de solo utilizado em áreas de pivô por caso observado (\% entrevistados). Fonte: Lima et al , 2017

Apesar de grande parte dos produtores rurais utilizarem a técnica do plantio direto em suas propriedades, alguns produtores têm se abdicado ou mesmo realizado a desconstituição de sistemas de terraceamento, alegando dificuldades de operar o maquinário agrícola. Contudo, os produtores rurais que são membros do CBH/AP relataram em suas entrevistas que os agricultores na Bacia do Rio Preto estão dispostos a adequar os terraços à operacionalização de suas máquinas agrícolas. Essa questão tem sido debatida nas reuniões do 
comitê, especialmente pela EMBRAPA Cerrados e a EMATER/DF. Os terraços têm a função de reduzir o escoamento das águas pluviais permitindo que a água se infiltre nas camadas do solo, abastecendo os reservatórios subterrâneos e, consequentemente, dando suporte as vazões dos cursos de água superficiais, além de evitar o surgimento ou agravo de processos erosivos na bacia. Considerando a escassez de água na bacia, percebe-se a necessidade da gestão se adaptar com essa situação.

Além das situações expostas acima, a governança adaptativa na Bacia do Rio Preto abrange a disponibilidade de crédito e incentivos financeiros nos moldes do Programa Produtor de Água, em que os produtores rurais são compensados financeiramente pelas práticas de conservação de solo e água que adotam em suas propriedades. O incentivo a pesquisa e o acesso à qualidade da assistência técnica especializada para implementação de medidas de uso racional da água reforçam a capacidade adaptativa na bacia. Este conjunto adaptativo, focado no aumento da eficiência hídrica dos sistemas agropecuários, contribui para reduzir a vulnerabilidade pela redução da demanda por água.

Outro conjunto de adaptações incide na gestão do uso do solo que priorize e fomente a capacidade de recarga dos aquíferos e proteja as nascentes e as matas ciliares. A capacidade adaptativa, neste caso, poderia ser analisada a partir do arcabouço legal que regula o uso da terra (código florestal, políticas de conservação ambiental, áreas de conservação em pontos de captação-chave, capacidade técnica dos órgãos gestores). De modo geral, as Áreas de Preservação Permanente e as reservas legais nas propriedades rurais da Bacia do Rio Preto estão em desconformidade com o exigido pela legislação ambiental. $\mathrm{Na}$ pesquisa de Lima et al (2017) foi constatado que muitos produtores rurais realizam intervenções em áreas próximas a nascentes para captação de água (figura 5).

Considerando a fragilidade de áreas de nascentes, os usuários que captam água à jusante e a redução das vazões dos corpos hídricos no período seco, a governança adaptativa na Bacia do Rio Preto deve abranger ações protetivas e diretrizes de uso racional da água nessas áreas. No Distrito Federal o órgão gestor dos recursos hídricos, que concede as Outorgas de Direito de Uso dos Recursos Hídricos, é a ADASA/DF, enquanto que a Licença Ambiental, exigida para empreendimentos/atividades voltados para a irrigação, é expedida pelo Instituto Brasília Ambiental -IBRAM/DF. Devido à falta de integração dos dados entre as instituições, outorgas para uso de água são concedidas sem considerar os aspectos ambientais da bacia (APP, reserva legal, áreas protegidas). 


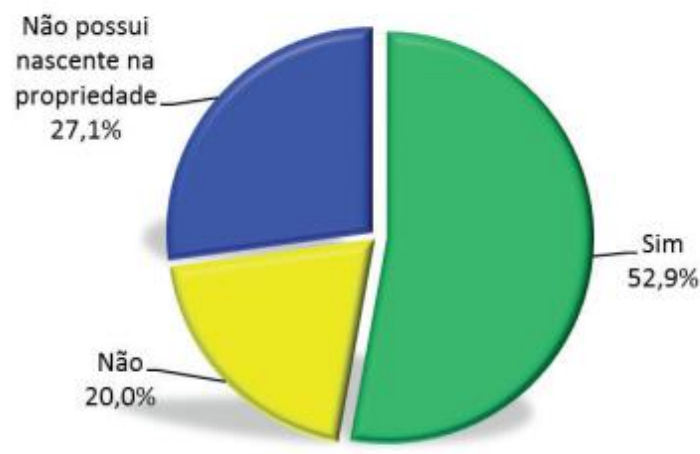

Figura 5 - Produtores que realizam a captação de água próximo à área de nascente. Fonte: LIMA et al, 2017.

A vazão ecológica é definida por resolução da ADASA/DF que estabelece um valor fixo de $20 \%$ da vazão de referência. Vestena (2012) aponta que a definição de valores fixos de vazões remanescentes baseados em dados hidrológicos históricos não é suficiente para a manutenção dos processos ecológicos na bacia. Tendo em vista que a vazão ecológica deve atender a manutenção ecológica na bacia, não é razoável que este valor seja fixo, baseado apenas em dados hidrológicos históricos e definido por um órgão que não tem atribuições de avaliar a conservação ambiental no território. O procedimento da outorga no Distrito Federal não contempla também aspectos de uso e ocupação de solo na bacia, fragilizando a eficiência desse instrumento. O CBH/AP ainda não foi capaz de interferir na adequação da revisão de outorgas. Na realidade o comitê não elaborou o Plano de Bacia que deveria, entre outros objetivos, prever as outorgas prioritárias, as metas de racionalização, a disponibilidade e a demanda dos recursos hídricos na bacia.

Previamente a instalação da crise hídrica no Distrito Federal, as concessões de outorgas foram permissivas regularizando usuários em diferentes bacias hidrográficas, mesmo naquelas em que a demanda já se aproximava do limite da oferta. A situação fica mais crítica quando se estima a quantidade de usuários irregulares atuando no território do DF. Na sub-bacia do Rio Jardim, inserida na Bacia do Rio Preto, quase $60 \%$ dos usuários de recursos hídricos são desconhecidos pela ADASA/DF, conforme verificado em dados presentes na apresentação técnica por servidor da referida agência em reunião do Comitê de Bacia Hidrográfica do Rio Preto no ano de 2016.

O licenciamento ambiental, um dos principais instrumentos da política ambiental, não consegue suprir os gargalos presentes nas concessões da outorga. A quantidade reduzida de analistas ambientais, a morosidade na análise dos processos, a ausência de dados ambientais integrados, a subjetividade dos analistas e a falta de padronização nas análises são fatores que comprometem a concessão das licenças ambientais. O CBH/AP ainda não possui influência na tomada de decisão das concessões de licenças ambientais para a atividade de irrigação. Portanto, compreendendo as fragilidades institucionais e de implantação dos instrumentos de controle, a crise hídrica no Distrito Federal despertou a atenção dos gestores e da sociedade para rever procedimentos de gestão e comportamento. 
Após a constatação da crise hídrica no DF, o poder público e a sociedade têm incorporado, ainda que timidamente, a necessidade de mudança no trato dos recursos hídricos. A ADASA/DF revisou seus procedimentos para concessão de outorgas. A agência realizou Audiência Pública para revisão dos procedimentos para concessão de outorga, expediu resoluções que regulam o uso de água por caminhões-pipa, por lava jatos, por instituições públicas, por produtores rurais e pela concessionária de saneamento e abastecimento urbano do DF (CAESB). A Secretaria de Agricultura do DF, em parceria com a EMATER/DF, tem promovido a revitalização de canais de irrigação nas comunidades rurais. A fiscalização dos usuários tem sido realizada de forma mais intensa. Os proprietários rurais da Bacia Hidrográfica do Rio Preto, entrevistados na pesquisa de Mesquita (2017), têm despertado a necessidade de uso de técnicas de conservação de água e solo com apoio de extensionistas rurais, em especial a adoção do plantio direto. A sociedade civil e instituições de ensino e pesquisa têm se mobilizado para desenvolver projetos que promovem a conservação e uso racional da água. O Ministério Público tem cobrado das instituições do DF ações de enfrentamento a crise hídrica. Contudo, essas ações foram focadas na Bacia Hidrográfica do Rio Descoberto devido a sua importância em fornecer o abastecimento de água para $65 \%$ da população urbana do DF. Portanto, comunidades rurais localizadas em outras bacias hidrográficas no Distrito Federal como na Bacia Hidrográfica do Rio Preto e na Bacia Hidrográfica do Rio São Bartolomeu ficaram desassistidas no gerenciamento dos recursos hídricos. Núcleos rurais nas regiões administrativas de Planaltina e de São Sebastião (Tabatinga, Rio Preto, Pipiripau), que dependem de sistemas de captação de fio de água ou captação por poços artesianos e tubulares, passam por períodos de restrição superiores aos estabelecidos para população urbana abastecida pelos reservatórios do Descoberto e de Santa Maria. No caso de comunidades rurais em que não há atendimento pela CAESB, ao invés de racionamento insere-se o cenário de completo desabastecimento. No período de seca do ano de 2017 foi registrado pela ADASA/DF cursos de água da Bacia do Rio Preto com seu leito seco ou com pequena lâmina de água, incapaz de utilização para abastecimento humano. Pequenos produtores que não tem condições financeiras de perfurar poços profundos são diretamente prejudicados. Para os irrigantes que fazem parte do $\mathrm{CBH} / \mathrm{AP}$ a solução da escassez de água na bacia é a construção de barragens. As barragens realmente podem aumentar a oferta de água na bacia. No entanto, também podem ser fonte de mais atrito entre os irrigantes e de outros problemas. As barragens devem ser adequadamente alocadas, construídas ou operadas. No caso da região da Bacia do Rio Preto no DF, onde predominam pequenas bacias com pequenas vazões, este cuidado não pode ser descartado (LIMA et al, 2017). Analisando os registros nas atas de reunião do $\mathrm{CBH} / \mathrm{AP}$ no período do ano de 2010 ao $1^{0}$ trimestre do ano de 2017, constatou-se que o assunto mais debatido no $\mathrm{CBH} / \mathrm{AP}$, desde sua criação, é a implantação de barramentos de cursos de água na Bacia do Rio Preto, principalmente pelo setor dos grandes irrigantes. Contudo, o órgão ambiental do DF tem se posicionado de forma contrária a implantação dessas estruturas nos processos de licenciamento ambiental.

Considerando os aspectos abordados previamente, percebe-se que a capacidade adaptativa se relaciona com as questões de governança. O comitê tem potencialmente papel fundamental na mediação dessas ações, promovendo a resolução de conflitos, negociação do uso da água e planejamento da gestão da bacia. Contudo, o comitê precisa inserir a participação de setores relevantes 
que estão excluídos dos debates, captar recursos com elaboração de projetos voltados a práticas conservacionistas, elaborar e executar o Plano de Bacia. O Quadro 01 apresenta algumas intervenções adaptativas que atuariam tanto na gestão da demanda e consumo como na gestão territorial da área da bacia.

Quadro 1 - Desafios e propostas resolutivas na gestão dos recursos hídricos na Bacia Hidrográfica do Rio Preto.

\begin{tabular}{|c|c|}
\hline DESAFIOS & PROPOSTAS RESOLUTIVAS \\
\hline $\begin{array}{l}\text { AUMENTAR A DISPONIBILIDADE DE } \\
\text { ÁGUA (1) }\end{array}$ & $\begin{array}{l}\text { - Incentivar a implementação de } \\
\text { projetos de compensação } \\
\text { financeira para usuários que } \\
\text { adotem práticas de conservação } \\
\text { de água e solo; } \\
\text { - Difundir e incentivar o uso de } \\
\text { técnicas de irrigação poupadoras } \\
\text { de água; } \\
\text { - Regularizar os usuários de água } \\
\text { na bacia. }\end{array}$ \\
\hline $\begin{array}{l}\text { ADAPTAÇÃO À ESCASSEZ DE ÁGUA } \\
\text { (3) }\end{array}$ & $\begin{array}{l}\text { - Estabelecer mecanismos de } \\
\text { avaliação, acompanhamento e } \\
\text { controle por parte dos usuários } \\
\text { com supervisão do poder público; } \\
\text { - Considerar, na análise para } \\
\text { concessão da outorga, aspectos } \\
\text { ambientais, uso e ocupação do } \\
\text { solo e as águas subterrâneas; } \\
\text { - Ampliar a participação de } \\
\text { instituições de ensino e pesquisa } \\
\text { na definição dos critérios para } \\
\text { concessão da outorga; } \\
\text { Unificar os dados de diferentes } \\
\text { setores (agrícola, ambiental, } \\
\text { recursos hídricos e uso e } \\
\text { ocupação do solo) referentes às } \\
\text { propriedades rurais na bacia. } \\
\text { Estabelecer indicadores de } \\
\text { avaliação (seca e escassez); } \\
\text { Inserir no Plano de } \\
\text { Gerenciamento Integrado dos } \\
\text { Recursos Hídricos do Distrito } \\
\text { Federal o cenário de escassez de } \\
\text { água na bacia, indicando metas } \\
\text { de racionalização, medidas }\end{array}$ \\
\hline
\end{tabular}




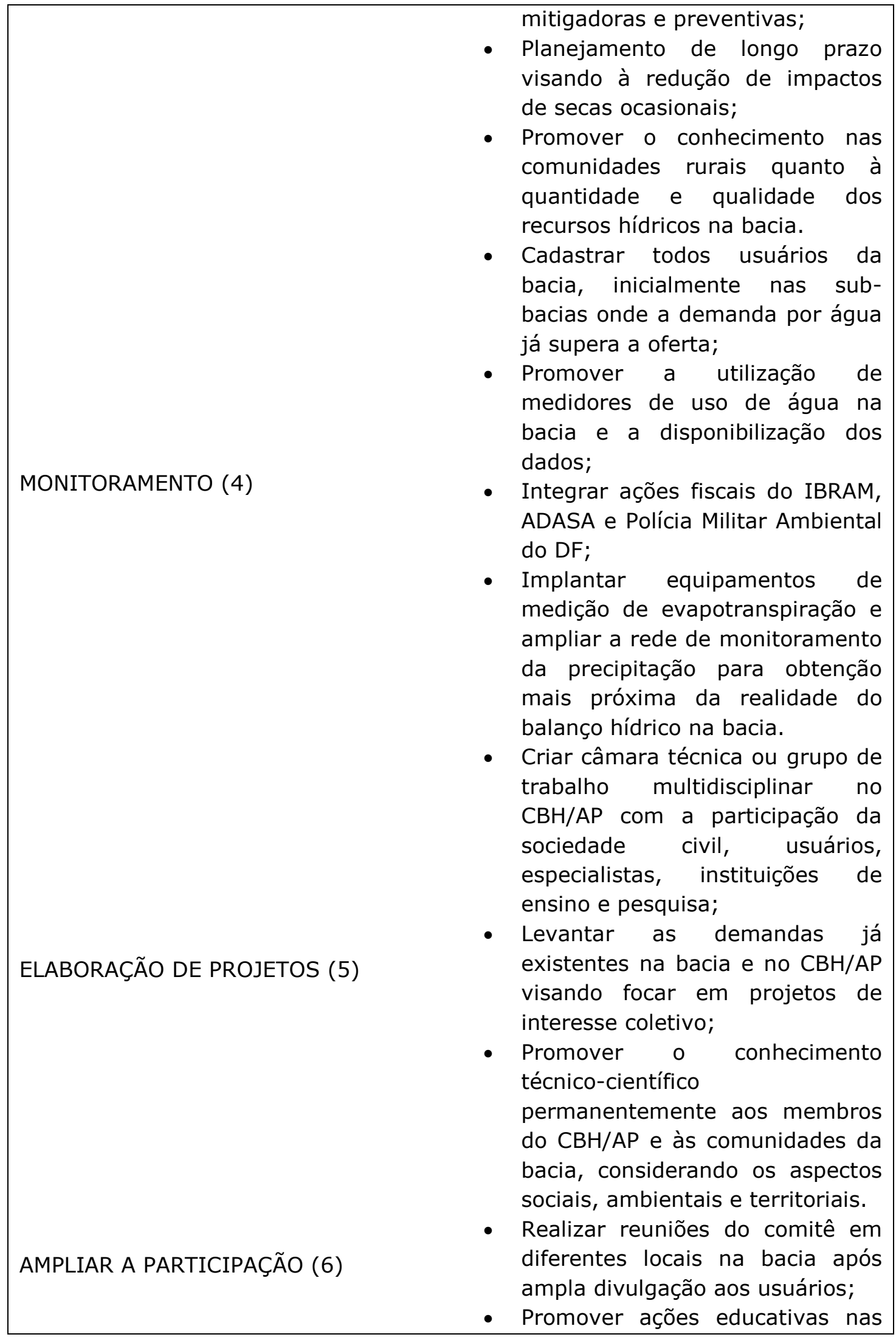




\begin{tabular}{|ll}
\hline comunidades de forma a \\
empoderá-las nos processos de \\
tomada de decisão; \\
Definir critérios de representação \\
nos organismos de bacia, de \\
forma a impedir tanto a \\
manipulação por grupos guiados \\
por interesses próprios, como a \\
possibilidade da \\
instrumentalização pela \\
administração pública; \\
Motivar os atores envolvidos na \\
gestão dos recursos hídricos na \\
bacia.
\end{tabular}

\section{CONCLUSÕES}

A crise hídrica vivenciada pelo Distrito Federal nos anos de 2015, 2016 e 2017 não decorreu apenas da redução de precipitações (abaixo das médias históricas) mas também da ocupação desordenada do solo, do descumprimento da legislação ambiental e do planejamento precário no que se refere aos aspectos ecológicos, sociais e de interesse coletivo.

Neste artigo foram trabalhados os aspectos da governança climática adaptativa no âmbito do Comitê de Bacia Hidrográfica dos Afluentes do Rio Preto-CBH/AP e sua relação com os atributos de exposição e sensibilidade.

Os comitês de bacias são instituições de gestão local que permitem a participação dos usuários e da sociedade civil no processo de tomada de decisão e são responsáveis, entre outras atribuições, por arbitrar os conflitos de uso de água, aprovar projetos e Plano de Bacias.

A área de atuação do CBH/AP é a Bacia Hidrográfica do Rio Preto. Nesta bacia o uso e ocupação do solo são predominantemente atividades agrícolas, especialmente culturas irrigadas. A bacia é o principal polo de produção agrícola que atua no Distrito Federal. O uso intensivo da irrigação na bacia aliado à redução das precipitações tem reduzido a disponibilidade de água para os diferentes usuários. A demanda pelo uso da água já supera a oferta em algumas sub-bacias inseridas na Bacia do Rio Preto. Neste contexto, o CBH/AP, gestor da bacia, insere-se como peça fundamental na governança climática.

Ao analisar o funcionamento do $\mathrm{CBH} / \mathrm{AP}$ constatou-se que a instituição não executa a maior parte das atribuições que lhe foram atribuídas. A alocação negociada de água na Bacia do Rio Preto é realizada entre a ADASA/DF, EMATER/DF e os produtores rurais. Apesar dessas instituições possuírem representantes membros do comitê, as reuniões de negociação ocorrem fora do âmbito dessa instituição, enfraquecendo sua consolidação. O comitê enfrenta dificuldades financeiras, carência de recursos humanos, predomínio do setor de 
grandes irrigantes, ausência da academia e dos pequenos produtores. Há forte pressão do setor de irrigação para implantação de barragens na bacia. Contudo, devido às restrições ambientais essa solução não tem avançado. Apesar das fragilidades constatadas no comitê, perceber-se alguns avanços. Na maioria das reuniões são discutidos dados científicos e técnicos principalmente pela EMBRAPA Cerrados e ADASA/DF, expondo aos produtores a situação hídrica crítica na bacia e medidas de conservação da água e solo a serem adotadas pelos produtores. Gradativamente, os produtores rurais têm incorporado essa necessidade de racionalizar o uso de água, bem como adotar práticas conservacionistas em suas propriedades. Dessa forma, à medida que o comitê vai se fortalecendo vai ganhando espaço na tomada de decisão e se aproximando de ações coletivas de interesse público.

Para avaliar os fatores que podem subsidiar o fortalecimento da governança adaptativa climática no âmbito do CBH/AP é preciso entender as relações entre os vetores de exposição e as sensibilidades climáticas. Para isso, foi elaborada uma cadeia de relações entre as atividades agrícolas e o uso de água na Bacia do Rio Preto. Na exposição da cadeia foi possível constatar quais pontos seriam passíveis de sofrer intervenções adaptativas. A revisão dos procedimentos para concessão de outorga de direito de uso de água, o uso de técnicas de conservação de água e solo, o uso racional da água, a recomposição/recuperação de APM, APP e de reserva legal são pontos de intervenção que devem ser levados em consideração na governança climática adaptativa.

Por fim, foi elaborado um quadro-síntese com os desafios e propostas resolutivas para o gerenciamento dos recursos hídricos na Bacia Hidrográfica do Rio Preto. Esse quadro foi elaborado com base nos dados coletados no âmbito do $\mathrm{CBH} / \mathrm{AP}$ e em dados coletados na literatura científica e governamental.

Incentivar a implantação de projetos de compensação financeira para usuários que adotarem práticas de conservação de água e solo em suas propriedades; utilizar tecnologias que poupem água; regularização dos usuários; inserir critérios ambientais, sociais e de uso e ocupação do solo na concessão das outorgas de água; inserir cenários de escassez no Plano de Bacia indicando metas de racionalização e ampliar a participação no $\mathrm{CBH} / \mathrm{AP}$ com representação de pequenos produtores e instituições acadêmicas são ações que podem subsidiar de forma positiva a agenda hídrica no Distrito Federal.

\section{REFERÊNCIAS BIBLIOGRÁFICAS}

ADGER, W. N.; Vulnerability. Global Environmental Change, v. 16, n. 3, p. 268$281,2006$.

ADGER, W. N.; KELLY, P. M. Social Vulnerability to Climate Change and the Architecture of Entitlements. Mitigation and Adaptation Strategies for Global Change, v. 4, n. 3/4, p. 253-266, 1999.

Agência Nacional de Águas (Brasil). ANA. Plano Nacional de Segurança Hídrica.Disponível em: <http://interaguas.ana.gov.br/Lists/Licitacoes_Docs/Attachments/32/TDR_PNS H_Preliminar. pdf $>$. acesso em 15 de maio de 2018 . 
BABEL, M.; SHINDE, V. Um quadro para a avaliação da segurança da água à escala da bacia. Boletim da Ciência da APN, 8 (1). doi: 10.30852 / sb.2018.342, 2018.

BANCO ASIÁTICO DE DESENVOLVIMENTO (BAD). Panorama do Desenvolvimento da Água na Ásia: Medindo a Segurança da Água na Ásia e no Pacífico, Manila, Filipinas.2013.

BECK, M.B.; VILLARROEL Walker, R.On water security, sustainability, and the water-food-energy-climate nexus. R. Front. Environ. Sci. Eng. (2013) 7: 626.

BORGES et al. Emprego do Processamento Digital dos Parâmetros Morfométricos no Mapeamento Geomorfológico da Bacia do Rio Preto. Espaço\& Geografia, v. 10, n. 2, p. 401-429, 2007.

BROOKS, N. Vulnerability, Risk and Adaptation: A Conceptual Framework, Working Paper 38, Tyndall Centre for Climate Change Research, 16 p., 2003, disponível em http://www.tyndall.ac.uk/sites/default/files/wp38.pdf, acesso em 15 de janeiro de 2012.

CARNEIRO, P. J. R. ; MALDANER , V.I.;ALVES, P.F; QUEIRÓS, I.A.; MAURIZ, T.V.; PACHECO, R.F. Evolução do uso da água na Bacia do Rio Preto no Distrito Federal. Espaço \& Geografia, v. 10, n. 2, p. 325-353, 2007.

CHAVES, Henrique M. L. Integrated sustainability analysis of six Latin-American basins. Journal of Hydrologic Environment, v. 7, p. 149-153, 2011.

CHENG, J. et al. Discussing water security. China Water Resources, v. 1, p. 2123, 2004.

DIETZ, T.; OSTROM, E; STERN, P. The struggle to govern the commons. Science, v. 302, n. 5652, p. 1907-12, 2003.

DISTRITO FEDERAL, DF. Plano Integrado de Gerenciamento dos Recursos Hídricos do Distrito Federal - PIGRH/DF (2012). Disponível em http://www.adasa.df.gov.br/regulacao/planos. Acesso em 21/11/2016.

DOLABELLA, R. H. C. Caracterização agroambiental e avaliação da demanda e da disponibilidade dos recursos hidricos para a agricultura irrigada da Bacia Hidrografica do Rio Jardim, DF. Dissertação (Mestrado em Ecologia) Universidade de Brasília, DF. p.105. 1996.

FORD, J; SMIT, B; WANDEL, J. ; MACDONALD, J. Vulnerability to climate change in Igloolik, Nunavut: what we can learn from the past and present. Polar Record, v. 42, n. 2, p. 127-138, 2006.

FÜSSEL, H. M.; KLEIN, R. Climate Change Vulnerability Assessments: An Evolution of Conceptual Thinking. Climatic Change, v. 75, n. 3, p. 301-329, 2006.

GALLOPÍN, G. C. Linkages between vulnerability, resilience, and adaptive capacity. Global Environmental change, v. 16, n. 3, p. 293-303, 2006.

GUNDERSON, L.; PETERSON, G.; HOLLING, C. S. Practicing adaptive management in complex social-ecological systems. In: NORBERG, J.; CUMMING, G. S. (Eds.). Complexity theory for a sustainable future. New York: Columbia University Press, 2008. p. 223-245. 
HOLLING, C. S.; MEFFE, G. K. Command and control and the Pathology of Natural Resources Management. Conservation Biology, v. 10, n. 2, p. 328-337, 1996 .

LIMA, J. E. F. W.; ANTONINI, J. C. dos A.; BORGES, M. M.; ANDRADE, S. M. L. de; LOBATO, B. R.; ROCHA, F. E. de C.; CARVALHO, A. V. V. Demandas relacionadas às Culturas irrigadas no DF e propostas para pesquisa, extensão e política ppública. IN Expedição Safra Brasília 2016: soja, milho safrinha e culturas irrigadas: diagnóstico e prospecção de demandas para pesquisa, extensão rural e política pública. Brasília, DF: Seagri-DF, 2017, 355 p.

LINDOSO, D.; RODRIGUES-FILHO, S. (2016) 'Vulnerabilidade e adaptação: bases teóricas e conceituais da pesquisa', in Marcel Bursztyn \& Saulo Rodrigues Filho (eds.) O clima em transe: vulnerabilidade e adaptação da agricultura familiar. Rio de Janeiro: Garamond, 19-34, 2016.

LINDOSO, D. P. Adaptação à mudança climática: ciência, política e desenvolvimento sustentável. Clima com Cultura Científica - Pesquisa, Jornalismo e Arte, v. 2, p. 1, 2015.

LINDOSO, D.; ROCHA, J. D.; DERBOTOLI, N. PARENTE, I. I. C; EIRÓ, F. BURSZTYN, M.; RODRIGUES-FILHO. Agricultura Familiar e Mudanças Climáticas: avaliando a vulnerabilidade à seca no semiárido nordestino. In: SEROA da MOTA et al. (eds) Mudança do Clima no Brasil: aspectos econômicos, sociais e regulatórios. Brasília, IPEA, 275-298, 2011.

LOPEZ, A.V.; FREITAS, M.A.S.A alocação de água como instrumento de gestão de recursos hídricos: experiências brasileiras. REGA, v.4, n. 1, p. 5-28, jan./jun. 2007.

MACHADO, B.G.F. Análise econômica aplicada à decisão sobre alocação de água entre os usos irrigação e produção de energia elétrica: o caso da bacia do Rio Preto. Dissertação (mestrado em tecnologia ambiental e recursos hídricos). Universidade de Brasília.p.145, 2009.

MADRUGA, R.R.G.;SILVA, T.N.;BEURON,T.;BLOCK,A. Comitê de Bacia: Uma Configuração Social Emergente na Gestão Sustentável das Águas. Desenvolvimento em Questão,n.18,jul/dez,2011,p.79-110.

MARANDOLA, E.; HOGAN, D. J. Natural hazards: o estudo geográfico dos riscos e perigos. Ambiente \& Sociedade, n. 2, p. 95-109, 2004.

MARENGO, J.A.; NOBRE A.C.; SELUCHI, M. E. ;CUARTAS, A. ; ALVES, L.M. MEDIONDO, E.M. ;OBREGON G. ; SAMPAIO, G. A seca e a crise hídrica de 20142015 em São Paulo. Revista USP, São Paulo, n. 106, p. 31-44 julho/agosto/setembro 2015.

MESQUITA, L. F. G. Gestão de Recursos Hídricos na Bacia Hidrográfica do Rio Preto: Atores, Ações e Conflitos. Dissertação de Mestrado. Centro de Desenvolvimento Sustentável da Universidade de Brasília, CDS/UnB.Brasília DF, $2017.182 \mathrm{p}$.

MOSER, S. C. Wheter our levers are long wnough and the fulcrum strong? Exploring the soft underbelly of adaption and actions. In: ADGER, W. NEIL; LORENZONI, I.; O'BRIEN, K. L. (Eds.). Adapting to climate change: thresholds, values, governance. Cambridge University Press, 2009. 
MOTTA, R.; HARGRAVE, J.; LUEDEMANN, G.; GUTIERREZ, M. B. S. (Eds.). Climate change in Brazil: economic, social and regulatory aspects. Brasilia: IPEA, p. 235-256, 2011.

NORBERG, J.; CUMMING, G. S; Introduction. In: NORBERG, J.; CUMMING, G. S. (Eds.). Complexity theory for a sustainable future. New York: Columbia University Press, p. 1-7, 2008.

O'BRIEN, K. L.; LEICHENKO, R. M. Double exposure: assessing the impacts of climate change within the context of economic globalization. Global Environmental Change, v. 10, n. 3, p. 221-232, 2000.

O’BRIEN, K. L.; LEICHENKO, R. M.; KELKAR, U.; VENEMA, H.; AANDAHL, G.; TOMPINKS, H.; JAVED, A.; BHADWAL, S.; BARG, S.; NYGAARD, L.; WEST, J.; Mapping vulnerability to multiple stressors: climate change and globalization in India. Global Environmental Change, v. 14, n. 4, p. 303-313, 2004.

PARRON, L. M. OLIVEIRA, E.C. Avaliação de qualidade das águas no brasil: o rio preto examinado. Espaço \& Geografia, v. 10, n. 2, p. 279-294, 2007

SMIT, B. et al. Adaptation to Climate Change in the Context of Sustainable Development and Equity, Climate Change 2001: Impacts, Vulnerability and Adaptation, Contribution of Working Group II to the Third Assessment Report of the Intergovernmental Panel on Climate Change, Oxford, 2001.

SMITHERS, J.; SMIT, B. Human adaptation to climatic variability and change. Global Environmental Change, v. 7, n. 2, p. 129-146, 1997

VESTENA, L. R.; OliveiRA, E. D.; CUNHA, M. C.; THOMAZ, E. L. Vazão ecológica e disponibilidade hídrica na bacia das Pedras, Guarapuava-PR. AmbiAgua, Taubaté, v. 7, n. 3, p. 212-227, 2012.

WHITE, G. F.; KATES, R. W; BURTON, I. Knowing better and losing even more\%: the use of knowledge in hazards management. Environmental hazards, v. 3, p. $81-92,2001$. 